\title{
The modified BODE index: validation with mortality in COPD
}

\author{
C.G. Cote*, V.M. Pinto-Plata\#, J.M. Marin`, H. Nekach, L.J. Dordelly ${ }^{+}$and B.R. Celli ${ }^{\#}$
}

ABSTRACT: Peak oxygen uptake $\left(\mathrm{V}^{\prime} \mathrm{O}_{2}\right)$ remains the gold standard measurement of exercise capacity and has been associated with survival. A modified BODE (body mass index, airflow obstruction, dyspnoea, exercise capacity) index replacing the 6-min walk distance (6MWD) with $V^{\prime} \mathrm{O}_{2}$ as \% predicted (mBODE\%) has been developed and found to have excellent correlation with the conventional BODE index.

The objectives of the present study were to compare the ability of the conventional BODE and the $\mathrm{mBODE} \%$ to predict mortality in $\mathbf{4 4 4}$ patients with chronic obstructive pulmonary disease (COPD) followed for a mean \pm SD period of $71 \pm 34$ months. Anthropometrics, spirometry, lung volumes, comorbidity, cardiopulmonary cyclo-ergometry test and 6MWD were determined at entry.

The mean BODE indices for the cohort were: BODE $4.1 \pm 2$ and $\mathrm{mBODE} \% 5.5 \pm 2$. Both indices were significantly correlated with mortality. Logistic regression analysis with COPD survival as the dependent variable identified the BODE index, Charlson's and exercise capacity (in W) as variables associated with this outcome.

In conclusion, the conventional BODE index, which uses the 6-min walk distance, predicts mortality in chronic obstructive pulmonary disease as well as the modified index using peak oxygen uptake. The results support the use of the simpler index, which includes the 6-min walk distance in the comprehensive evaluation of patients with chronic obstructive pulmonary disease.

KEYWORDS: Chronic obstructive pulmonary disease, exercise capacity, mortality

$\mathbf{T}$ he oxygen uptake measured at peak exercise $\left(V^{\prime} \mathrm{O}_{2}\right)$ during incremental cardiopulmonary exercise testing (CPET) is considered to be the gold standard for the evaluation of exercise capacity. $V^{\prime} \mathrm{O}_{2}$ helps predict survival in patients undergoing lung resection $[1,2]$ and lung volume reduction surgery (LVRS) [3], and in patients with chronic obstructive pulmonary disease (COPD) [4] and heart failure [5]. The 6-min walk test (6MWT) is easy to perform and has been standardised [6], and also predicts mortality in COPD $[7,8]$ and in pulmonary hypertension [9].

The 6MWT is considered a submaximal test; however, CASAS et al. [10] have shown that patients with COPD walk at a pace close to their maximal exercise capacity while the $V^{\prime} \mathrm{O}_{2}$ measured at the end of an incremental protocol in COPD is not a true maximal oxygen uptake [11, 12]. This indicates that the differences between tests in the patients with COPD may not be as large as otherwise suspected. There is a modest but significant correlation between $V^{\prime} \mathrm{O}_{2}$ and 6min walking distance (6MWD) [13, 14], implying that the tests are not equal; however, as it relates to the capacity to predict survival in COPD, the current authors have recently shown that the $6 \mathrm{MWD}$ is equal to, if not better than, $V^{\prime} \mathrm{O}_{2}$ at predicting this outcome [15].

The BODE index, which incorporates measurements of nutrition (body mass index), airflow obstruction (forced expiratory volume in one second (FEV1)), dyspnoea (Modified Medical Research Council dyspnoea scale) and exercise capacity as measured by the $6 \mathrm{MWD}$, predicts mortality [16, 17], hospitalisations [18] and reflects disease modification after LVRS [19], nonsurgical volume reduction [20], and pulmonary rehabilitation [21]. It also reflects the deleterious effects of exacerbations and hospitalisations [22].

CARDOso et al. [23] recently developed a modified BODE index (mBODE) by replacing the 6MWD with $V^{\prime} \mathrm{O}_{2}$. An excellent correlation between BODE and mBODE when the $V^{\prime} \mathrm{O}_{2}$ value was expressed as $\%$ predicted was reported $(\mathrm{mBODE} \%)$, which was better than with that with mBODE when $V^{\prime} \mathrm{O}_{2}$ was expressed in $\mathrm{mL} \cdot \mathrm{kg}^{-1} \cdot \mathrm{min}^{-1}$.

The purpose of the present study was to test the hypothesis that the $\mathrm{mBODE} \%$ index using $V^{\prime} \mathrm{O}_{2}$ expressed as \% pred had a similar predictive
AFFILIATIONS

*Pulmonary and Critical Care, Bay Pines Veterans Administration Medical Center,

+The Bay Pines Research Foundation, Bay Pines, FL,

\#Pulmonary and Critical Care, Caritas St. Elizabeth's Medical Center, Boston, MA, USA. -Hospital Miguel Servet, Zaragoza, Spain.

CORRESPONDENCE

C.G. Cote

Pulmonary and Critical Care Medicine

Bay Pines Veterans Administration Health Care System

10,000 Bay Pines Boulevard Bay Pines FL 33744 USA

Fax: 17273191090

E-mail: claudia.cote@med.va.gov

Received:

October 212007

Accepted after revision: June 162008

STATEMENT OF INTEREST None declared. 


\begin{tabular}{|c|c|c|}
\hline TABLE 1 & \multicolumn{2}{|c|}{$\begin{array}{l}\text { Baseline characteristics in a cohort of } 444 \\
\text { patients with chronic obstructive pulmonary } \\
\text { disease }\end{array}$} \\
\hline \multicolumn{3}{|l|}{ Variable } \\
\hline \multicolumn{2}{|l|}{ Subjects $n$} & 444 \\
\hline \multicolumn{2}{|l|}{ Age yrs } & $66 \pm 8(37-83)$ \\
\hline \multicolumn{2}{|c|}{ Smoking history pack-yrs } & $80 \pm 44(10-250)$ \\
\hline \multicolumn{2}{|l|}{$\mathrm{Pa}_{\mathrm{a}, \mathrm{O}_{2}} \mathrm{mmHg}$} & $72 \pm 11(52-96)$ \\
\hline \multicolumn{2}{|l|}{$\mathrm{BMI} \mathbf{k g} \cdot \mathrm{m}^{-2}$} & $26.9 \pm 5.4(14-50)$ \\
\hline \multicolumn{2}{|l|}{ FEV $1 \%$} & $41 \pm 15(15-90)$ \\
\hline \multicolumn{2}{|l|}{ FVC \% } & $73 \pm 17(32-120)$ \\
\hline \multicolumn{2}{|l|}{ FEV $1 /$ FVC $\%$} & $44 \pm 12(16-70)$ \\
\hline \multicolumn{2}{|l|}{ MMRC } & $2.3 \pm 0.8(0-4)$ \\
\hline \multicolumn{2}{|l|}{ 6MWD m } & $367 \pm 114(54-712)$ \\
\hline \multicolumn{2}{|l|}{ BODE index } & $4.11 \pm 2(0-10)$ \\
\hline \multicolumn{2}{|c|}{ mBODE\% index } & $5.5 \pm 2(0-10)$ \\
\hline
\end{tabular}

Data are presented as mean \pm SD (range), unless otherwise stated. $\mathrm{Pa}_{\mathrm{a}} \mathrm{O}_{2}$ : partial arterial pressure of oxygen; BMI: body mass index; FEV1: forced expiratory volume in one second; FVC: forced vital capacity; MMRC: Modified Medical Research Council dyspnoea scale; 6MWD: 6-min walking distance; mBODE\%: modified BODE index using peak oxygen uptake as \% predicted.

power for mortality to the original BODE index, which includes the $6 \mathrm{MWD}$ in a cohort of patients with COPD.

\section{METHODS}

\section{Patients}

The cohort consisted of 444 patients with COPD, recruited at the Bay Pines Veterans Administration Health Care System (Bay Pines, FL, USA; n=292), St Elizabeth's Medical Center (Boston, MA, USA; $\mathrm{n}=119$ ) and the Miguel Servet Hospital (Zaragoza, Spain; n=33) between 1996 and 2006 and followed until June 2008. The human research committees at each institution approved the study and all patients gave informed consent. Enrolment criteria have been previously published
[16]. The patients were clinically stable for 6 weeks and had to be able to perform both tests.

\section{Measurements}

Spirometry and 6MWD were completed following the American Thoracic Society (ATS) recommendations [6, 24]. Comorbidity was determined with the Charlson score [25]. For exercise ergometry, the patients started with a 2-min period of unloaded pedalling at $60 \mathrm{cycles} \cdot \mathrm{min}^{-1}$, followed by a 10 $15 \mathrm{~W} \cdot \mathrm{min}^{-1}$ increment [26] and were encouraged to cycle until exhaustion. Heart rate and blood pressure were monitored continuously. Minute ventilation and its components were measured using a pneumotachograph. The concentrations of expired oxygen and carbon dioxide were analysed breath by breath. The present study used 30-s averages of minute ventilation, tidal volume, respiratory rate, oxygen uptake, carbon dioxide output and gas exchange ratio. Predicted maximal oxygen consumption was calculated using standard equations [26]. The heart rate reserve was calculated as 220 minus the patient's age minus the observed peak heart rate. CPET and the 6MWD were performed on separate days, at least 1 day apart and within 1 month of enrolment into the study. To avoid bias, the two tests were performed in random order.

\section{The BODE indices}

The BODE index was calculated as previously reported [16]. The $\mathrm{mBODE} \%$ index was calculated by replacing the $6 \mathrm{MWD}$ by the $V^{\prime} \mathrm{O}_{2}$ expressed as \% pred as follows: score 0 for $>70 \%$ pred; score 1 for $60-69 \%$ pred; score 2 for $40-59 \%$ pred; and score 3 for $<40 \%$ pred [27]. In the study of CARDOSO et al. [23], as well as in calculations conducted in the present cohort (data not presented), the $V^{\prime} \mathrm{O}_{2}$ expressed as \% pred offered similar, if not better, discriminating power than the absolute value.

\section{Statistical analysis}

The data are presented as mean \pm SD and range. The differences in physical characteristics, pulmonary function test and exercise parameters in patients stratified by BODE quartiles were evaluated using ANOVA. Pearson's correlation test was used to assess the relationship between the indices and mortality. Mortality was evaluated over time using Kaplan-Meier analysis.

\begin{tabular}{|c|c|c|c|c|c|c|c|c|}
\hline \multirow[t]{2}{*}{ Variable } & \multicolumn{2}{|c|}{ Quartile 1} & \multicolumn{2}{|c|}{ Quartile 2} & \multicolumn{2}{|c|}{ Quartile 3} & \multicolumn{2}{|c|}{ Quartile 4} \\
\hline & BODE & mBODE\% & BODE & mBODE\% & BODE & mBODE\% & BODE & mBODE\% \\
\hline Exercise capacity w & $97 \pm 32$ & $104 \pm 36^{*}$ & $71 \pm 24$ & $82 \pm 26^{\star}$ & $53 \pm 19$ & $64 \pm 22^{*}$ & $34 \pm 16$ & $45 \pm 18^{\star}$ \\
\hline Resting $f c$ beats $\cdot \min ^{-1}$ & $91 \pm 16$ & $88 \pm 15$ & $93 \pm 15$ & $94 \pm 15$ & $98 \pm 13$ & $95 \pm 15$ & $99 \pm 10$ & $97 \pm 13$ \\
\hline Peak $f c$ beats $\cdot \mathrm{min}^{-1}$ & $127 \pm 16$ & $130 \pm 15$ & $121 \pm 18$ & $130 \pm 15$ & $119 \pm 15$ & $120 \pm 16$ & $114 \pm 18$ & $117 \pm 17$ \\
\hline fc reserve \% & 26 & 22 & 32 & 28 & 33 & 32 & 39 & 36 \\
\hline Maximal V'E L & $68 \pm 21$ & $61 \pm 20$ & $49 \pm 19$ & $58 \pm 19^{\star}$ & $40 \pm 13$ & $49 \pm 19^{\star}$ & $31 \pm 10$ & $35 \pm 10^{*}$ \\
\hline$V^{\prime} E \mathrm{~L} \cdot \min ^{-1}$ & $54 \pm 18$ & $72 \pm 21^{*}$ & $41 \pm 12$ & $49 \pm 13^{*}$ & $36 \pm 10$ & $40 \pm 21^{*}$ & $30 \pm 9$ & $32 \pm 9$ \\
\hline
\end{tabular}

Data are presented as mean $\pm \mathrm{SD}$, unless otherwise stated. $V^{\prime} \mathrm{O}_{2}$ : oxygen uptake; $f \mathrm{C}$ : cardiac frequency; $V^{\prime} \mathrm{E}:$ minute ventilation. ${ }^{*}: \mathrm{p}<0.05$ 


\begin{tabular}{|c|c|c|c|c|}
\hline TABLE 3 & $\begin{array}{l}\text { Logistic regression anal) } \\
\text { (ORs) for survival among } \\
\text { obstructive pulmonary d }\end{array}$ & $\begin{array}{l}\text { sis and odds } \\
\text { patients with } \\
\text { sease }\end{array}$ & rat & $\begin{array}{l}\text { os } \\
\text { ronic }\end{array}$ \\
\hline \multirow[t]{2}{*}{ Parameter } & \multirow[t]{2}{*}{ OR (95\% Cl) } & \multicolumn{3}{|c|}{ Likelihood ratio test } \\
\hline & & Chi-squared & Df & p-value \\
\hline BODE & 0.738009 (0.72834-0.747806) & 14.7321 & 1 & 0.0001 \\
\hline Charlson & $0.90021(0.888416-0.91216)$ & 3.88384 & 1 & 0.0487 \\
\hline $\begin{array}{l}\text { Exercise } \\
\text { capacity }^{\#}\end{array}$ & $1.02158(1.0082-1.03514)$ & 11.1606 & 1 & 0.0008 \\
\hline
\end{tabular}

Logistic regression analysis was used to investigate the relationship between the indexes and mortality. Receiver operating curves (ROC) were used to assess the diagnostic power of both indices with mortality as an outcome. A p-value $<0.05$ was considered significant.

\section{RESULTS}

The characteristics of the 444 patients are shown in table 1 . The cohort was predominantly male (87\%) and Caucasian (99\%), and $23 \%$ of the patients were oxygen dependent. Using ATS/ European Respiratory Society (ERS)/Global Initiative for Chronic Obstructive Lung Disease (GOLD) criteria, 2\% were classified as stage 1 COPD patients, $27 \%$ were stage $2,47 \%$ were stage 3 and $24 \%$ were stage 4 . When the patients were stratified by the conventional BODE index, 23\% were in quartile 1, 35\% were in quartile 2, 29\% were in quartile 3 and $13 \%$ were in quartile 4 . Conversely, when stratified by $\mathrm{mBODE} \%, 10 \%$ were in quartile $1,22 \%$ were in quartile 2 , $32 \%$ were in quartile 3 and $36 \%$ were in quartile 4 . The mean BODE index for the cohort was $4.11 \pm 2$ and the $\mathrm{mBODE} \%$ index was $5.5 \pm 2.1(\mathrm{p}<0.001)$ with a difference of 1.4 points.
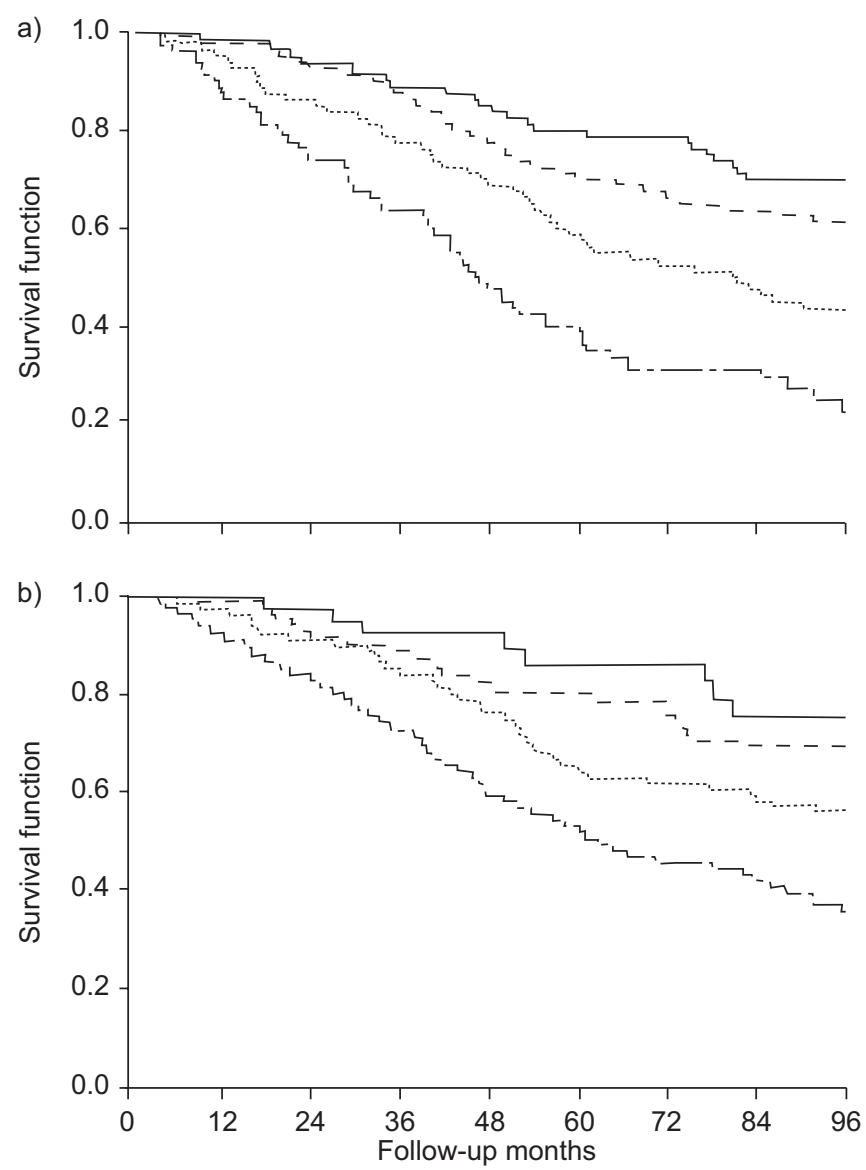

FIGURE 1. Kaplan-Meier survival curves for a) the original BODE index that uses the 6-min walk distance and b) the modified BODE index (mBODE\%) using the peak oxygen uptake $\%$ predicted. Both are divided in quartiles as follows. quartile 1 (BODE or mBODE\% index score $0-2$ ); - - --: quartile 2 (score $3-4$ ); $\ldots$. . quartile 3 (score $5-6) ;-\cdot \cdot \cdot \cdot-$ : quartile 4 (score $7-10$ ). The original index differentiated to a level similar to that of the modified BODE. See also table 4

\section{TABLE 4 Survival probability of chronic obstructive pulmonary disease patients stratified by BODE and modified BODE $(\mathrm{mBODE} \%)$ indices}

Survival probability \%

Baseline 12 months 24 months 36 months 48 months 60 months 72 months 84 months 96 months 8 -yr survival

\begin{tabular}{|c|c|c|c|c|c|c|c|c|c|c|}
\hline \multicolumn{11}{|l|}{ BODE } \\
\hline Quartile 1 & 102 & 101 & 96 & 92 & 88 & 84 & 83 & 76 & 76 & 74.5 \\
\hline Quartile 2 & 156 & 154 & 147 & 136 & 122 & 112 & 106 & 103 & 99 & 63.4 \\
\hline Quartile 3 & 130 & 125 & 113 & 102 & 91 & 78 & 70 & 65 & 61 & 46.9 \\
\hline Quartile 4 & 56 & 50 & 42 & 36 & 27 & 23 & 18 & 18 & 14 & 25 \\
\hline \multicolumn{11}{|l|}{ mBODE\% } \\
\hline Quartile 1 & 44 & 44 & 43 & 41 & 41 & 39 & 39 & 36 & 36 & 81.8 \\
\hline Quartile 2 & 95 & 94 & 88 & 85 & 79 & 77 & 73 & 68 & 68 & 71.5 \\
\hline Quartile 3 & 143 & 141 & 131 & 122 & 111 & 94 & 90 & 86 & 83 & 58 \\
\hline Quartile 4 & 162 & 151 & 136 & 113 & 97 & 87 & 75 & 72 & 63 & 38.9 \\
\hline
\end{tabular}

Quartile 1: BODE or mBODE\% index score 0-2; quartile 2: score 3-4; quartile 3: score 5-6; quartile 4: score 7-10. See also figure 1. 


\section{Exercise parameters}

Table 2 shows that the exercise capacity was severely reduced at all stages except for quartile 1, whether patients were stratified by the traditional BODE index or the modified BODE index. The present authors observed that only $39(8.7 \%)$ patients in the cohort had normal exercise capacity $\left(V^{\prime} \mathrm{O}_{2}>70 \%\right.$ pred). With exemption of cardiac parameters, which showed no differences, BODE reflected exercise impairment better than the mBODE.

\section{Mortality}

There were 206 deaths during the study, with a mean \pm SD time from enrolment to death of $22 \pm 29$ months. A total of 107 (51.4\%) were due to COPD and $40(19.4 \%)$ to lung cancer. The remaining deaths were due to cardiovascular disease, cancers other than lung cancer and other medical reasons. Mortality was very high for patients who had a $V^{\prime} \mathrm{O}_{2}<40 \%$ pred $(61 \%)$ or a walking distance $<350 \mathrm{~m}(63 \%)$. Conversely, COPD mortality among patients exceeding these values was low (18 and $15 \%$, respectively).

Logistic regression analysis identified the conventional BODE index, Charlson's comorbidity and exercise capacity as variables associated with COPD mortality. The model explained $17.16 \%$ of the deviance; odds ratios are shown in table 3. Kaplan-Meier survival analysis (fig. 1 and table 4) also identified a better stratification between BODE quartiles than mBODE\% quartiles. The Chi-squared for BODE was 58 versus 40 for $\mathrm{mBODE} \%$ $(p \leqslant 0.00001)$. Mortality was higher in all of the conventional BODE quartiles, in particular in quartile 4, compared with the corresponding $\mathrm{mBODE} \%$ index quartile. An ROC analysis showed discriminative values of 0.73 for BODE and 0.72 for $\mathrm{mBODE} \%$ (fig. 2).

\section{Correlations}

Pearson's correlation calculations between the indices were performed and they were found to correlate very well (fig. 3).

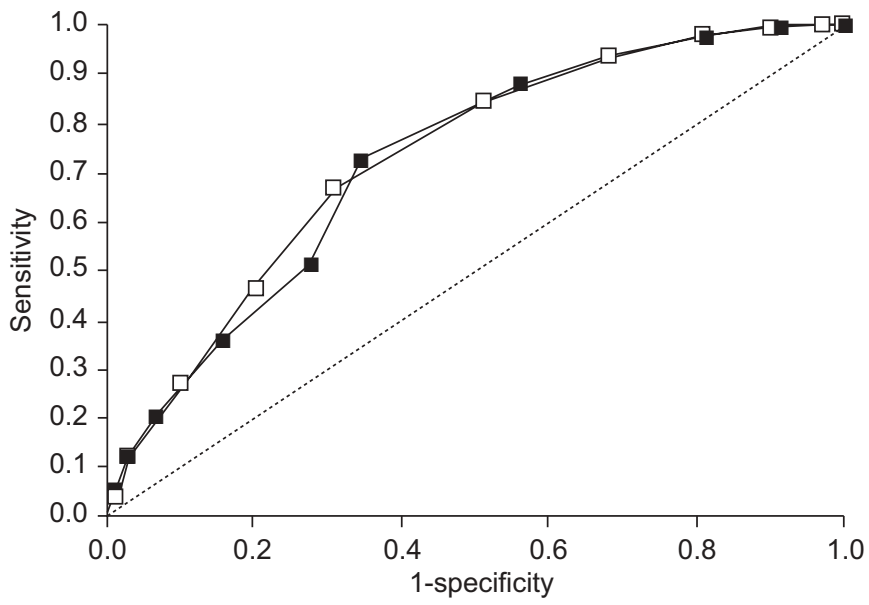

FIGURE 2. Receiver operating curves for the conventional BODE index ( $\square$ ) using the 6-min walk distance and the modified BODE index (mBODE\%; $\mathbf{0})$ using peak oxygen uptake \% predicted. No differences were observed between tests in their capacity to predict survival in chronic obstructive pulmonary disease. The area under the curve for the BODE index was 0.73 (95\% confidence interval $(\mathrm{Cl}) 0.67-0.79$; SE 0.029). The corresponding value for $\mathrm{mBODE} \%$ was 0.72 (95\% $\mathrm{Cl} 0.66-0.78$; SE 0.030).
The correlation between 6MWD and $V^{\prime} \mathrm{O}_{2}$ was modest but highly statistically significant, as it has been demonstrated previously.

\section{DISCUSSION}

The present study shows that in patients with a wide range of COPD severity, the conventional BODE index predicts mortality as well as the modified BODE index which replaces the $6 \mathrm{MWD}$ with $V^{\prime} \mathrm{O}_{2} \%$ pred obtained during CPET.

The current authors have previously shown that the BODE index is a better predictor of mortality than FEV1 [16]. The BODE index also predicts hospitalisations and outcome following LVRS and pulmonary rehabilitation [17-21]. The BODE index incorporates the 6MWD as a measure of exercise capacity. Different modifications of the conventional BODE index have been proposed, among them one that incorporates $V^{\prime} \mathrm{O}_{2}$ and not the 6MWD. In one study, the modified BODE index was reported to have an excellent correlation with the conventional BODE $(r=0.97)$ but its predictive value for mortality was not evaluated [23]. In the present study, these findings of CARDOSO et al. [23] were confirmed, and the modest
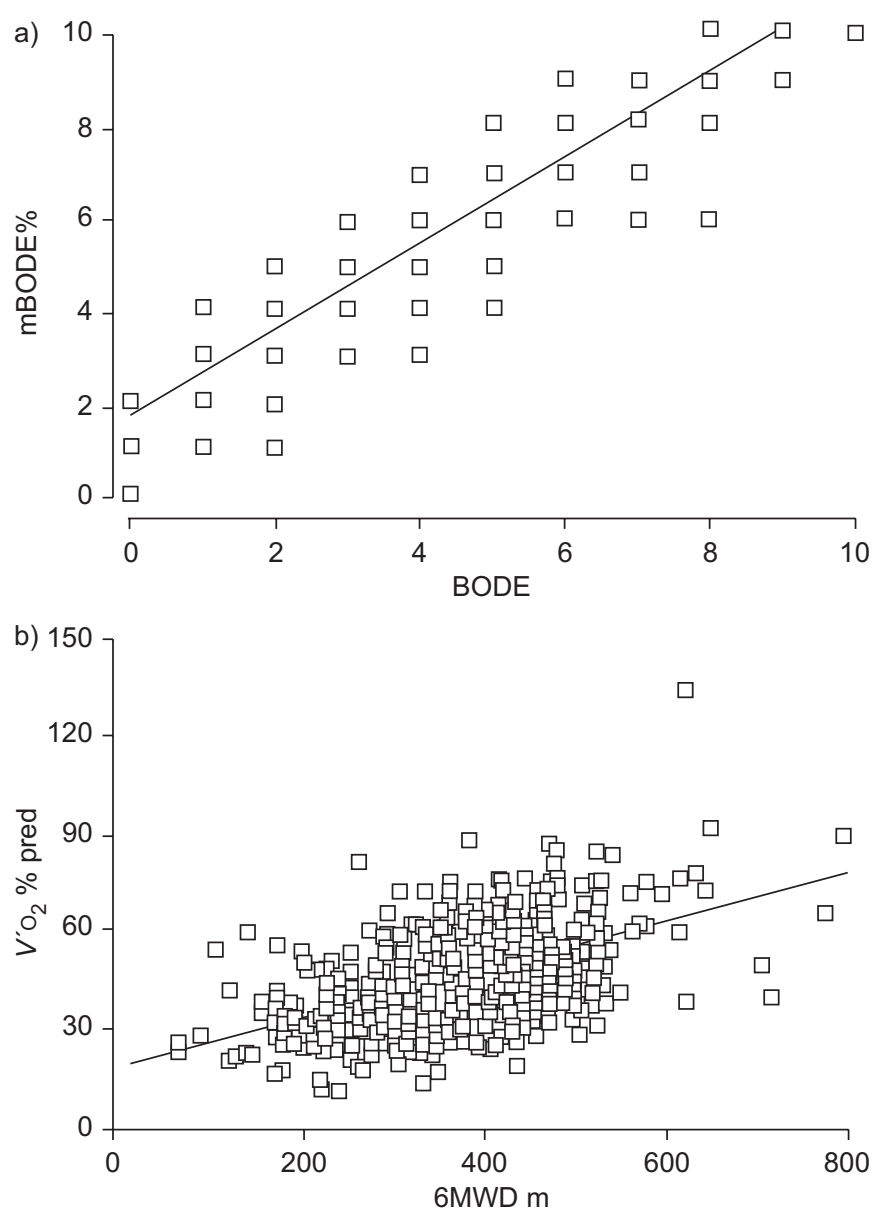

FIGURE 3. a) Pearson's correlations between the traditional BODE index and the modified BODE index (mBODE\%). Although the correlation between the two indexes is excellent, b) a more modest but significant correlation is seen between 6min walk distance (6MWD) and peak oxygen uptake $\left(\mathrm{V}^{\prime} \mathrm{O}_{2}\right)$. 
but significant correlation between the 6MWD and $V^{\prime} \mathrm{O}_{2} \%$ pred was further corroborated.

Indeed, it seems logical that $V^{\prime} \mathrm{O}_{2}$, which represents the integral function of the cardiopulmonary system, should be superior at predicting outcome in COPD and to reflect better the multisystemic compromise of these patients than the 6MWD. It is also reasonable to expect that the $6 \mathrm{MWD}$, which is considered a submaximal test, to have less of an overall predictive capacity, because it has been thought of as being less objective and accurate than $V^{\prime} \mathrm{O}_{2}$. Surprisingly, as shown in figures 1 and 2 , the conventional BODE index, which uses 6MWD, performed equally well, if not better than, the modified BODE index using $V^{\prime} \mathrm{O}_{2}$ the prediction of mortality in this cohort of patients.

It is possible that the different methodology during CPET influences the information obtained with this test. An incremental load protocol during exercise testing may not be sustainable for patients with more severe COPD. Indeed, in the present cohort of 444 patients ( $27 \%$ stage 1 and 2, as defined by ATS/ERS/GOLD) only 39 (8.7\%) patients had $V^{\prime} \mathrm{O}_{2}>70 \%$ pred. This impairment in exercise capacity, even at lower stages of ATS/ERS/GOLD disease severity, has been reported before and its aetiology is not clear. Unsuspected pulmonary hypertension, right ventricular afterload and impaired oxygen utilisation have been proposed to be possible mechanisms [27].

When patients in ATS/ERS/GOLD stages 0-2 (120 patients, $27 \%$ of the cohort) were analysed separately, their $V^{\prime} \mathrm{O}_{2}$ was only $57 \pm 16 \%$ pred, which suggests that this methodology of testing with incremental load might not be sustainable, even for patients with mild disease. It is likely that the patients in the present cohort developed symptoms of shortness of breath and/or leg fatigue, which made them stop the exercise before they reached a "true" $V^{\prime} \mathrm{O}_{2}$. As seen in table 2, all patients had a reduced breathing reserve at all stages of disease by BODE and $\mathrm{mBODE} \%$ indices. Conversely, when patients are physically unable to walk more than a very short distance during the $6 \mathrm{MWD}$, in spite of being allowed to pace themselves and to pause as needed, this inability to walk may represent a greater vital compromise than that provided by a reduced $V^{\prime} \mathrm{O}_{2}$.

The present study has some limitations. First, the patients included here were mostly males attending specialised centres and, therefore, the findings may not be extended to female patients or to COPD patients attending other settings. However, the wide range of airflow obstruction in the cohort represent most patients with COPD seen by clinicians. Secondly, only patients capable of performing both tests were included. Thus, the results may not apply to patients with conditions that limit the ability to walk.

In summary, the present study has shown that, in patients with a wide range of chronic obstructive pulmonary disease severity, the conventional BODE index using the 6-min walk distance is as good a predictor of mortality as the modified BODE index using peak oxygen uptake (expressed as \% predicted) obtained in a cardiopulmonary exercise test, but is much simpler to obtain. These results support the incorporation of simple practical tests to evaluate the multidimensional compromise of patients with chronic obstructive pulmonary disease.

\section{REFERENCES}

1 Weisman I. Cardiopulmonary exercise testing in the preoperative assessment for lung resection surgery. Sem Thorac Cardiovasc Surg 2001; 13: 116-125.

2 Bolliger C, Perruchoud A. Functional evaluation of the lung resection candidate. Eur Respir J 1998; 11: 198-212.

3 Szekely L, Oelberg D, Wright C, et al. Preoperative predictors of operative mortality in COPD patients undergoing bilateral lung volume reduction surgery. Chest 1997; 111: 550-558.

4 Oga T, Nishimura K, Tsukino M, Sato S, Hajiro T. Analysis of the factors related to mortality in chronic obstructive pulmonary disease. Role of exercise capacity and health status. Am J Respir Crit Care Med 2002; 167: 544-549.

5 Lauer M, Snader C. Using exercise test to prognosticate patients with heart failure. Which parameter should we measure? Cardiol Clin 2001; 19: 573-581.

6 ATS Committee on Proficiency Standards for Clinical Function Laboratories. American Thoracic Society Statement: guidelines for the six-minute walk test. Am J Respir Crit Care Med 2002; 166: 111-117.

7 Gerardi DA, Lovett L, Benoit-Connors ML, Reardon JZ, ZuWallack RL. Variables related to increased mortality following out-patient pulmonary rehabilitation. Eur Respir J 1996; 9: 431-435.

8 Pinto Plata V, Cote CG, Cabral HJ, Taylor J, Celli B. The 6minute walk distance: change over time and value as predictor of survival in severe COPD. Eur Respir J 2004; 23: 28-33.

9 Miyamoto S, Nagaya N, Satoh T, et al. Clinical correlates and prognostic significance of 6 minute walk in patients with pulmonary hypertension. Comparison with cardiopulmonary exercise testing. Am J Respir Crit Care Med 2000; 161: 487-492.

10 Casas A, Vilaro J, Rabinovich R, et al. Encouraged 6-min walking test indicates maximum sustainable exercise in COPD patients. Chest 2005; 128: 55-61.

11 Montes de Oca M, Rassulo J, Celli B. Respiratory muscle function and cardiopulmonary function during exercise in very severe COPD. Am J Respir Crit Care Med 1996; 154: 1284-1289.

12 Casaburi R, Patessio A, Ioli F, Zanaboni S, Donner CF, Wasserman K. Reductions in exercise lactic acidosis and ventilation as a result of exercise training in patients with chronic obstructive lung disease. Am Rev Respir Dis 1991; 143: 9-18.

13 Montes de Oca M, Ortega M, Lezama J, López JM. Enfermedad pulmonar obstructiva crónica. Evaluación de la tolerancia al ejercicio utilizando tres tipos diferentes de prueba de esfuerzo. [Chronic obstructive pulmonary disease: evaluation of exercise tolerance using three different exercise tests]. Arch Bronconeumol 2001; 37: 69-74.

14 Swinburn CR, Wakefiel JM, Jones PW. Performance, ventilation, and oxygen consumption in three different types of exercise test in patients with chronic obstructive lung disease. Thorax 1985; 40: 581-586.

15 Cote CG, Pinto-Plata V, Kasprzyk K, Dordelly LJ, Celli BR. The 6-min walk distance, peak oxygen uptake and mortality in COPD. Chest 2007; 132: 1778-1785. 
16 Celli BR, Cote CG, Marin JM, et al. The body mass index, airflow obstruction, dyspnea, and exercise capacity index in chronic obstructive pulmonary disease. $N$ Engl J Med 2004; 350: 1005-1012.

17 Imfeld S, Bloch KE, Weder W, et al. The BODE index after lung volume reduction correlates with survival in COPD. Chest 2006; 129: 835-836.

18 Ong, KC, Earnest A, Lu SJ, et al. A multidimensional grading system (BODE index) as predictor of hospitalization for COPD. Chest 2005; 128: 3810-3816.

19 Martinez FJ, Foster G, Curtis JL, et al. Predictors of mortality in patients with emphysema and severe airflow obstruction. Am J Respir Crit Care Med 2006; 173: 1326-1334.

20 Pompeo E, Mineo TC. Two-year improvement in multidimensional body mass index, airflow obstruction, dyspnea, and exercise capacity index after nonresectional lung volume reduction surgery in awake patients. Ann Thorac Surg 2007; 84: 1862-1869.

21 Cote CG, Celli BR. Pulmonary rehabilitation and the BODE index in COPD. Eur Respir J 2005; 26: 630-636.
22 Cote CG, Dordelly LJ, Celli BR. Impact of exacerbations on patient-centered outcomes. Chest 2007; 131: 696-704.

23 Cardoso F, Tufanin AT, Colucci M, Nascimento O, Jardim JR. Replacement of the 6-min walk test with maximal oxygen consumption in the BODE index applied to patients with COPD: an equivalency study. Chest 2007; 132: 477-482.

24 American Thoracic Society Statement. Lung function testing: selection of reference values and interpretative strategies. Am Rev Resp Dis 1991; 144: 1202-1218.

25 Charlson M, Szatrowski TP, Peterson J, Gold J. Validation of a combined comorbidity index. J Clin Epidemiol 1994; 47: 1245-1251.

26 American Thoracic Society, American College of Chest Physicians. ATS/ACCP Statement on cardiopulmonary exercise testing. Am J Respir Crit Care Med 2003; 167: 211-277.

27 Carter R, Nicrota B, Blevins W, Holiday D. Altered exercise gas exchange and cardiac function in patients with mild chronic obstructive pulmonary disease. Chest 1993; 103: 745-750. 